\title{
Management of Clavicular Fracture in Adults by Plating : A Systematic Review
}

\author{
S.A.Khaleel, M.A.Meselhy, S.A.Al-Traigy and A.M.Shosha
}

Orthopedic Surgery Dept., Faculty of Medicine, Benha Univ., Benha, Egypt

E-Mail:Shosha@gmail.com

\begin{abstract}
The management of the clavicular fracture still controversy between conservative treatment and surgical intervention. Also the methods of the surgical interventions have different variety between plates and screws, IMN and $\mathrm{K}$ wires. We review previous publications comparing the the different approaches and types of plates used in the surgical interventions with the aim of determining if any of the available interventions gives better outcomes compared to others. A systematic literature review of previous publications on the various techniques employed in the Management of clavicular fracture in adults by plating. We suggest that where the expertise is available, intervention by minimally invasive techniques should be preferred to the conventional open surgical approaches. If otherwise, the choice of operative technique should simply be based on the experience of the surgeon, the available facilities and equipment.
\end{abstract}

Keywords: Acute clavicular fractures, Fracture clavicle fixation by plates, Types of plates for clavicular fixation and minimal invasive plate fixation of fracture clavicle.

\section{Introduction}

Clavicle is the anterior member of the shoulder girdle extending from the manubrium sterni to the acromion process and representing the only bony connection between the upper extremity and the axial skeleton [1] .It presents as S shaped tubular bone with a double curvature, convex anteriorly in the medial two thirds and concave anteriorly in the lateral third [2].

Fractures were classified based on their anatomic location in descending order of fracture incidence [3]. Type I fractures occur within the middle third of the clavicle, whereas type II and type III fractures represent involvement of the lateral and medial thirds, respectively [4].

A more detailed classification system [Edinburgh classification] was proposed by Robinson, Similar to earlier descriptions, the primary classification is anatomically divided into medial [type I], middle [type II], and lateral [type III] thirds [5].

\begin{tabular}{|l|}
\hline Type 1Medial \\
A: Non-displaced \\
A1: Extra-articular \\
A2: Intra-articular \\
B: Displaced \\
B1: Extra-articular \\
B2: Intra-articular \\
Type 2Middle \\
A: Cortical alignment \\
A1: Non-displaced \\
A2: Angulated \\
B: Displaced \\
B1: Simple or single butterfly fragment \\
B2: Comminuted or segmental \\
Type 3Distal \\
A: Non-displaced \\
A1: Extra-articular \\
A2: Intra-articular \\
B: Displaced \\
B1: Extra-articular \\
B2: Intra-articular \\
\hline
\end{tabular}

A direct blow on the point of the shoulder is the commonest reported mechanism of injury that produces a mid-shaft fracture of the clavicle [6].

Most authors, who have written on the treatment of fracture clavicle, recommended a conservative approach [7]. However, studies showed higher rates of nonunion, malunion and poor functional outcomes after conservative treatment. Hence, authors have suggested that a subset of patients may be best treated by operative intervention $[8,9]$.

Biomechanically, locking plates are identical to external fixators as the angular stability between the plate and screws means that the plate does not need to be in contact with the bone. This creates the option to use mono-cortical screws, negates the need for inferior cortex penetration and reduces the risk of brachial plexus and subclavian vessels injury [10].

Some risk factors are discovered to predispose to fracture nonunion including local and general factors, the local factors are type II distal fractures, open fractures, soft tissue interposition[11], shortening [12] or displacement of $\geq 20 \mathrm{~mm}$, refracture[13],increased comminution and inadequate method and/or duration of initial immobilization [14], while the general factors are old age, female sex, diabetes mellitus, smoking, malnutrition and steroid intake [5].

The aim of this study is to review the different indications and techniques of plating of clavicular fractures also the results and the complications of each technique.

\section{Materials and methods \\ Method and selection criteria [Search strategy]}

The literature search was done using the following electronic databases: PubMed, SCOPUS, Web of Science, and The Cochrane Library. The search strategies were developed and edited by the authors to maximize the sensitivity. The search strategy included several different terms and synonyms for clavicle and clavicular fracture in combination with plating, surgical treatment and surgical approach, functional ability or physical activity.

\section{Eligibility}

We depended a strategy in this review in which the primary measured outcomes were symptomatic hardware [implant prominence or irritation] and infection rate. The secondary outcomes were fracture union, nonunion, malunion, Disabilities of the Arm, 
Shoulder and Hand score, Constant score, and implant failure. Both primary and secondary outcomes were extracted from the studies according to their availability, as it was common for studies to examine some but not all the outcomes.

\section{Literature search [Selection of studies]}

The initial database search yielded 98 articles. Fifty one studies remained after removing duplicate articles. After screening the abstracts and titles, 40 relevant studies were further excluded because of use of nonstandard plates, a subject pool not exclusively consisting of acute fractures, inadequate reporting of functional outcomes, a duplicate group of patients and inaccessible articles. So finally eleven articles were used in this systematic review. with total 2370 patients who underwent primary ORIF for claviclular fracture were included in the analysis, these were all the papers in our database who meet the inclusion criteria of the systematic review.

The key findings from these publications are as summarized in tables and discussed further in this paper Tables (1-3).

Table (1) Frequency of union, non-union, implant failure and postoperative infection among the enrolled studied patients in relation to approach and name of author $[\mathrm{n}=2370]$.

\begin{tabular}{|c|c|c|c|c|c|c|c|c|c|c|c|c|}
\hline \multirow[t]{3}{*}{ Approach } & \multicolumn{2}{|c|}{$\begin{array}{c}\text { Author [No. of } \\
\text { patients] }\end{array}$} & \multicolumn{10}{|c|}{ The enrolled studied patients $[\mathrm{n}=2370]$} \\
\hline & & & \multicolumn{2}{|c|}{ Union patients } & \multicolumn{2}{|c|}{$\begin{array}{c}\text { Non- } \\
\text { union } \\
\text { patients }\end{array}$} & \multicolumn{2}{|c|}{$\begin{array}{l}\text { Implant } \\
\text { failure }\end{array}$} & \multicolumn{2}{|c|}{$\begin{array}{l}\text { Postoperative } \\
\text { infection }\end{array}$} & \multicolumn{2}{|c|}{$\begin{array}{c}\text { Total patients } \\
{[\mathrm{n}=2370]}\end{array}$} \\
\hline & & & $\mathbf{N}$ & $\%$ & $\mathbf{N}$ & $\%$ & $\mathbf{N}$ & $\%$ & $\mathbf{N}$ & $\%$ & $\mathbf{N}$ & $\%$ \\
\hline \multirow{5}{*}{$\begin{array}{c}\text { Anterior } \\
\text { inferior }\end{array}$} & Sohn & [18] & 1394 & 96.8 & 46 & 3.2 & 50 & 3.5 & 35 & 2.4 & 1440 & 60.7 \\
\hline & Hulsmans & [39] & & & & & & & & & & \\
\hline & Alex Nourian & [1140] & & & & & & & & & & \\
\hline & Rafael & {$[118]$} & & & & & & & & & & \\
\hline & Xioben & {$[125]$} & & & & & & & & & & \\
\hline \multirow[t]{6}{*}{ Superior } & Sohn & [19] & 660 & 98.6 & 9 & 1.3 & 92 & 13.7 & 66 & 9.9 & 669 & 28.2 \\
\hline & Hulsmans & {$[60]$} & & & & & & & & & & \\
\hline & Alex Nourian & [390] & & & & & & & & & & \\
\hline & Rafael & [134] & & & & & & & & & & \\
\hline & Xioben & [34] & & & & & & & & & & \\
\hline & Erdle & [32] & & & & & & & & & & \\
\hline \multirow{4}{*}{$\begin{array}{l}\text { Direct } \\
\text { transverse }\end{array}$} & Raju & {$[32]$} & 236 & 98.3 & 4 & 1.7 & 35 & 14.6 & 7 & 2.9 & 240 & 10.1 \\
\hline & Alzahrani & [102] & & & & & & & & & & \\
\hline & Kingsly & [55] & & & & & & & & & & \\
\hline & Raghuraj & [16] & & & & & & & & & & \\
\hline MIPO & Raghuraj & [21] & 20 & 95.2 & 1 & 4.8 & 1 & 4.8 & 0 & 0 & 21 & 0.9 \\
\hline \multirow[t]{2}{*}{ Total } & & 2370 & 2310 & 97.5 & 60 & 2.5 & 17 & 7.5 & $108 / 2176$ & 5.0 & 2370 & 100 \\
\hline & & & & & & & 8 & & & & & \\
\hline
\end{tabular}

Table (2) Frequency of union, non-union, implant failure and postoperative infection among the enrolled studied patients in relation to type of plate and name of author [ $n=2370]$.

\begin{tabular}{|c|c|c|c|c|c|c|c|c|c|c|c|}
\hline \multirow[t]{3}{*}{ Type of plate } & \multirow[t]{3}{*}{ Author } & \multicolumn{10}{|c|}{$\begin{array}{l}\text { The enrolled studied patients } \\
{[n=2370]}\end{array}$} \\
\hline & & \multicolumn{2}{|c|}{$\begin{array}{c}\text { Union } \\
\text { patients }\end{array}$} & \multicolumn{2}{|c|}{$\begin{array}{c}\text { Non- } \\
\text { union } \\
\text { patients }\end{array}$} & \multicolumn{2}{|c|}{$\begin{array}{l}\text { Implant } \\
\text { failure }\end{array}$} & \multicolumn{2}{|c|}{$\begin{array}{l}\text { Postoperative } \\
\text { infection }\end{array}$} & \multicolumn{2}{|c|}{$\begin{array}{c}\text { Total } \\
\text { patients } \\
{[\mathrm{n}=2370]}\end{array}$} \\
\hline & & $\mathbf{N}$ & $\%$ & $\mathbf{N}$ & $\%$ & $\mathbf{N}$ & $\%$ & $\mathbf{N}$ & $\%$ & $\mathbf{N}$ & $\%$ \\
\hline $\begin{array}{l}\text { Non locking } \\
\text { reconstruction plate }\end{array}$ & $\begin{array}{l}\text { Rafael Alzahrani } \\
\text { Kingsly }[31 \mathrm{pt}]\end{array}$ & 379 & 98.4 & 6 & 1.6 & 65 & $\begin{array}{r}16 \\
9\end{array}$ & 9 & 2.3 & 385 & $\begin{array}{c}16 . \\
2\end{array}$ \\
\hline $\begin{array}{l}\text { locking reconstruction } \\
\text { plate }\end{array}$ & $\begin{array}{l}\text { Sohn Hulsmans } \\
\text { Xioben }\end{array}$ & 283 & 95.9 & 12 & 4.1 & 41 & $\begin{array}{l}13 \\
.9\end{array}$ & 6 & 2.0 & 295 & 12. \\
\hline $\begin{array}{l}\text { locking precontoured } \\
\text { plate }\end{array}$ & $\begin{array}{l}\text { Alex Nourian Kingsly } \\
\text { [24 pt.] Raghuraj }\end{array}$ & 1551 & 97.5 & 40 & 2.5 & 71 & $\begin{array}{c}4 . \\
5\end{array}$ & 93 & 5.8 & 1591 & $\begin{array}{c}67 . \\
1\end{array}$ \\
\hline Hook plate & Erdle Wonyong & 66 & 98.5 & 1 & 1.5 & 1 & $\begin{array}{l}1 . \\
5\end{array}$ & 0 & 0 & 67 & 2.8 \\
\hline $\begin{array}{l}\text { locking plate with } \\
\text { lateral extension }\end{array}$ & Raju & 31 & 96.9 & 1 & 3.1 & 0 & 0 & 0 & 0 & 32 & 1.3 \\
\hline Total & & 2310 & 97.5 & 60 & 2.5 & 178 & $\begin{array}{l}7 . \\
5\end{array}$ & $\begin{array}{l}108 / \\
2176\end{array}$ & 5.0 & 2370 & 100 \\
\hline
\end{tabular}


Table (3) Score among the enrolled studied patients.

\begin{tabular}{|c|c|c|c|}
\hline Authors & Outcome measure & Approach or Plate type & Score \\
\hline Sohn [15] & Constant score measure [26] & Ant. Inf. & $97.27 \pm 4.99$ point \\
\hline & & Superior & $95.75 \pm 4.25$ point \\
\hline Hulsmans [16] & Implant related irritation & Ant. Inf. & $22 \%$ \\
\hline & & Superior & $18 \%$ \\
\hline Alex Nourian [17] & The mean DASH score [27] & Ant. Inf. & 5.18 point \\
\hline $\begin{array}{l}\text { Erdle [18] } \\
\text { Rafael [19] }\end{array}$ & $\begin{array}{l}\text { The constant score } \\
\text { Implant related irritation }\end{array}$ & $\begin{array}{c}\text { Superior } \\
\text { Anterior superior } \\
\text { Ant. Inf. }\end{array}$ & $\begin{array}{l}9.71 \text { point } \\
90.3 \text { point } \\
5 \%\end{array}$ \\
\hline Raju [20] & The constant score & $\begin{array}{c}\text { Superior } \\
\text { Horizontal incision on distal clavicle }\end{array}$ & $\begin{array}{c}25 \% \\
96.25 \text { point }\end{array}$ \\
\hline Wonyong Lee[21] & The quick DASH score & $10 \mathrm{~cm}$ on distal clavicle & $1.4 \pm 0.9$ point \\
\hline Xioben [22] & Implant related irritation & $\begin{array}{l}\text { Ant. Inf. } \\
\text { Superior }\end{array}$ & $\begin{array}{l}11.4 \% \\
21.5 \%\end{array}$ \\
\hline Alzahrani [23] & The constant score & Transverse incision & 95.8 point \\
\hline Kingsly [24] & Quick DASH score & $\begin{array}{c}\text { Anatomical plate } \\
\text { Reconstruction plate }\end{array}$ & $\begin{array}{l}25.44 \text { point } \\
32.65 \text { point }\end{array}$ \\
\hline Raghuraj [25] & Quick DASH score & Open longitudinal & 4.1 point \\
\hline & & MIPO & 4.7 point \\
\hline
\end{tabular}

\section{Discussion}

The main finding of the present study is as follows: We had performed a systematic review of fixation techniques in unstable clavicle fracture patients. Four classes of surgical approaches and five different types of fixation plates have been used and studied :

\subsection{Surgical approaches}

Anterior inferior approach used in 5 papers with total patient number 1440 . It is considered one of the best approaches used in the review with the least complication rate [in relation to implant failure and infection] and good union rate [96.8\%].

Superior approach used in 6 papers with total patient number 669. Easy approach to use for fracture reduction and plate fixation. Despite the best union rate $[98.6 \%$ ] it has a very high complication rate according to implant failure [13.7\% ] and infection rate [9.9\%]

Direct transverse approach used in 4 papers with total patient number 240 . It is a direct incision across the fracture. Union rate is $98.3 \%$. this approach has the heist implant failure rate by $14.6 \%$ and infection rate $2.9 \%$.

Minimally invasive plate osteosynthesis [MIPO] used in only one paper with total patient number 21 . A difficult surgical approach in controlling the fracture but it preserves the vascularity of the clavicle. Union rate is $95.2 \%$. None of the cases has been infected but there is only one case [4.8\%] with implant failure.

\subsection{Plates}

Non locking reconstruction plate used in 3 papers with total patient number 385 and with union rate $98.4 \%$. It was the first plate to be used in the fixation of fracture clavicle but it shows high complication rate. In this study it has the heist rate of implant failure [16.9\% [and the infection rate was $2.3 \%$.

locking reconstruction plate used in 3 papers with total patient number 295 and with union rate $95.9 \%$. It provides more rigid fixation than the Non locking reconstruction plate specially with comminuted fractures so implant failure rate is lower [13.9\%] but the infection rate is higher than that of the Non locking reconstruction plate [4.1\%].

locking precontoured plate used in 3 papers with total patient number 1591 and with union rate $97.5 \%$. This is now the most common plate used in fixation of clavicle fractures specially the middle third fractures. In this study the implant failure rate is $4.5 \%$ and the infection rate is $5.8 \%$ which is the heist rate of infection among the study.

Hook plate a special plate for the lateral third clavicular fractures, used in 2 papers with total patient number 67 and with union rate $98.5 \%$. None of the cases has got infected but there is only one case [1.5\%] with implant failure.

locking plate with lateral extension also a special plate for the lateral third clavicular fractures as the hook plate, used in one papers with total patient number 32 and with union rate $96.9 \%$. None of the cases has got infected or has implant failure. It is just one patient $[3.1 \%]$ with non union.

\section{Conclusion}

Plate fixation has several advantages including

1- For transverse fractures, compression across the fracture site is achieved and for oblique fractures or butterfly fragments, a lag screw is possible with a neutralization plate.

2- [2]Secure rotational control of the fracture.

3- Fixation is rigid enough to allow early use of the arm for the activities of daily living. 


\section{Implications: \\ Two main surgical techniques for fracture plating \\ 1- open reduction and internal fixation \\ Anterosuperior plating: \\ It is the preferred technique because of the simple approach, the well proved clinical record and the several biomechanical studies suggesting that it is the optimal plate location.}

\section{Anteroinferior plating}

Advantages include easier screw entry, less risk of serious injury, the ability to insert longer screws in the wider AP dimension, decreased hardware prominence and easier plate contouring along the anterior border.

\section{Postoperative protocol}

An arm sling is used for comfort and gentle pendulum exercises are allowed. The patient is seen after10-14 days during which the wound is checked and radiographs are taken. The sling is discontinued and unrestricted ROM exercises are allowed. After 6 weeks, radiographs are taken to ensure bony union.

\section{Minimally invasive plate osteosynthesis [MIPO]}

MIPO has several advantages being safe, minimally invasive, biological, simple and effective procedure leading to rapid recovery, high union rate and function restoration as it reduces soft tissue disruption, preserves blood supply and lowers the chance of cutaneous nerve injury and scarring on the prominent plate.

clavicle fractures which fixed with $3.5 \mathrm{~mm}$ reconstruction plates were more likely to exhibit plastic deformation, whereas $2.7 \mathrm{~mm}$ plating constructs utilizing reconstruction plates where more likely to fail by plate breakage.

\section{References}

[1] J.R. Dugas, B.T. Kelly, S.J. O'Brien, 'Anatomy of the shoulder',In: Principles and practice of Orthopaedic sports medicine.1st edn. Philadelphia, Vol. 25(5), PP. 329-378,2000.

[2] S. Standring, 'Anatomy of the pectoral girdle, shoulder region and axilla', In:Gray's Anatomy, the anatomical basis of clinical\ practice, Vol.60, PP. 791-822,2008.

[3] R.I. Harris, D.H. Vu, D.H. Sonnabend, 'Anatomic variance of the coracoclavicular ligaments',J Shoulder Elbow Surg,Vol.10(6), PP. 585588,2001.

[4] P.M. Ludewig, V. Phadke, J.P. Braman, 'Motion of the Shoulder Complex During Multiplanar Humeral Elevation', J Bone Joint Surg Am,Vol. 91(2), PP. 378-389,2009.

[5] C.M. Robinson, 'Fractures of the clavicle in the adult. Epidemiology and classification',J Bone Joint Surg Br,Vol.80(3), PP. 476-484,1998.

[6] C.M. Robinson, 'Fractures of the clavicle in the adult Epidemiology and classification',J Bone Joint Surg Br,Vol.80(3), PP. 476- 484,1996.
[7] S. Kim, A. Blank, E. Strauss, 'Management of type 3 acromioclavicular joint dislocations - current controversies',Bull Hosp Jt Dis, Vol.72(1), PP. 5360,2014.

[8] M. Zlowodzki, B.A. Zelle, P.A. Cole, 'Treatment of midshaft clavicle fractures: systemic review of 2144 fractures: on behalf of the Evidence-Based Orthopaedic Trauma Working Group', J Orthop Trauma, Vol.19(7), PP. 504-507,2005

[9] K.A. Egol, E.N. Kubiak, E. Fulkerson, Biomechanics of locked plates and screws',J Orthop Trauma,Vol.18[8], PP. 488-493,2004.

[10]J.F. Baker, H. Mullett, "Clavicle non-union: autologous bone graft is not a necessary augment to internal fixation',Acta Orthop, Vol.70(8), PP.320-325,2010

[11]A.S. Rokito , J.D. Zuckerman, J.M. Shaari, 'A comparison of nonoperative and operative treatment of type II distal clavicle fractures', Vol.61(1-2), PP. 32-39,2003.

[12]M. Wick, E.J. Müller, E. Kollig, 'Midshaft fractures of the clavicle with a shortening of more than $2 \mathrm{~cm}$ predispose to nonunion',Arch Orthop Trauma Surg,Vol.121(4), PP. 207-211,2001.

[13]J.B. Jupiter, R.D. Leffert, 'Non-union of the clavicle. Associated complications and surgical management', J Bone Joint Surg Am,Vol.69 (5), PP. 753-760,1987.

[14]J.F. Baker, H. Mullett, 'Clavicle non-union: autologous bone graft is not a necessary augment to internal fixation',Acta Orthop Belg,Vol.76 (6), PP. 725-729,2010.

[15]Hoon-Sang Sohn, Min Soo Shon, Kyung-Hag Lee , []: 'Clinical comparison of two different plating methods in minimally invasive plate osteosynthesis for clavicular midshaft fractures',Injury, Vol.25 (5), PP.4622302238,2015.

[16] M.H. Hulsmans, M. van Heijl, R.M. Houwert, 'Anteroinferior versus superior plating of clavicular fractures',J Shoulder Elbow Surg.Vol. 25(3), PP.448-54,2016.

[17]A. Nourian, S. Dhaliwal, S. Vangala, Midshaft fractures of the clavicle: a meta-analysis comparing surgical fixation using Anteroinferior plating versus superior plating. Journal of orthopaedic trauma, Vol.31(9), PP.461-467,2017.

[18]B. Erdle, K. Izadpanah, M. Jaeger, 'Comparative Analysis of locking plate versus hook plate osteosynthesis of Neer type IIB lateral clavicle fractures', Arch Orthop Trauma Surg. 2017 May, Vol.137(5):651 662,2017.

[19] R. Serrano, A. Borade, H. Mir, A. Shah, Anteriorinferior plating results in fewer secondary interventions compared to superior plating for acute displaced midshaft clavicle fractures. Journal of orthopaedic trauma, vol . 31(9),PP. 468471,2005.

[20]Raju Vaishya, Vipul Vijay , Vikram Khanna. 'Outcome of distal end clavicle fractures treated 
with locking plates',Chin J Traumatol. Vol.20(1), PP. 45-48,2017.

[21] Wonyong Lee, Chong-Hyuk Choi, Yun-Rak Choi, 'Clavicle hook plate fixation for distal-third clavicle fracture [Neer type II]: comparison of clinical and radiologic outcomes between Neer types IIA and IIB', J Shoulder Elbow Surg , Vol.26, PP.1210-1215,2017.

[22] X. Chen, S. F. Shannon, M. Torchia, Radiographic outcomes of single versus dual plate fixation of acute mid-shaft clavicle fractures. Archives of orthopaedic and trauma surgery, Vol.137(6), PP.749-754.

[23] M.M. Alzahrani, A. Cota, K. Alkhelaifi, Are clinical outcomes affected bytype of plate used for management of mid-shaft clavicle fractures',JOrthop Traumatol, Vol.19(1), PP.8,2018.

[24]P. Kingsly, M. Sathish, N. D. M. Ismail, Comparative analysis of functional outcome of anatomical precontoured locking plate versus reconstruction plate in the management of displaced midshaft clavicular fractures. Journal of Orthopaedic Surgery, Vol.27(1), PP.320-325,2019

[25] R. Kundangar, K. A. Singh, S. P. Mohanty, Clinical outcome of internal fixation of middle third clavicle fractures using locking compression plate: Comparison between open plating and MIPO. Journal of orthopaedics, Vol.16(5), PP. 414-418,2018.

[26] C. Gummesson, M. M. Ward, I. Atroshi, The shortened disabilities of the arm, shoulder and hand questionnaire [Quick DASH]: validity and reliability based on responses within the fulllength DASH. BMC musculoskeletal disorders, Vol.7 (1), PP.44,2006.

[27]M. K. Gilbart, C. Gerber, Comparison of the subjective shoulder value and the Constant score. Journal of Shoulder and Elbow Surgery, Vol.16(6), PP. 717-721, 2007 